\title{
Assessment of Energy Savings Potential from the Use of Demand Controlled Ventilation in General Office Spaces in California
}

\author{
Tianzhen Hong and William J. Fisk \\ Environmental Energy Technologies Division \\ Lawrence Berkeley National Laboratory \\ Berkeley, CA 94720
}

January 2010

This document was prepared as an account of work sponsored by California Energy Commission under DOE Contract No. DE-AC02-05CH11231. 


\section{Assessment of Energy Savings Potential from the Use of Demand Controlled Ventilation in General Office Spaces in California}

\section{Abstract}

A prototypical office building meeting the prescriptive requirements of the 2008 California building energy efficiency standards (Title 24) was used in EnergyPlus simulations to calculate the energy savings potential of demand controlled ventilation (DCV) in five typical California climates per three design occupancy densities and two minimum ventilation rates. The assumed minimum ventilation rates in offices without $\mathrm{DCV}$, based on two different measurement methods employed in a large survey, were 38 and $13 \mathrm{~L} / \mathrm{s}$ per occupant. The results of the life cycle cost analysis show DCV is cost effective for office spaces if the typical minimum ventilation rate without $\mathrm{DCV}$ is $38 \mathrm{~L} / \mathrm{s}$ per person, except at the low design occupancy of 10.8 people per $100 \mathrm{~m}^{2}$ in climate zones 3 (north coast) and 6 (south Coast). DCV was not found to be cost effective if the typical minimum ventilation rate without $\mathrm{DCV}$ is $13 \mathrm{~L} / \mathrm{s}$ per occupant, except at high design occupancy of 21.5 people per $100 \mathrm{~m}^{2}$ in climate zones 14 (desert) and 16 (mountains). Until the large uncertainties about the base case ventilation rates in offices without DCV are reduced, the case for requiring DCV in general office spaces will be a weak case. Under the Title 24 Standards office occupant density of 10.8 people per $100 \mathrm{~m}^{2}$, DCV becomes cost effective when the base case minimum ventilation rate is greater than 42.5, 43.0, 24.0, 19.0, and $18.0 \mathrm{~L} / \mathrm{s}$ per person for climate zone $3,6,12,14$, and 16 respectively.

\section{Keywords}

Building Simulation, Building Energy Standard, Demand Controlled Ventilation, Energy Savings

\section{Introduction}

Adequate ventilation with outdoor air is critical for occupants living or working in buildings. Too much or too little outdoor air in an occupied space can cause problems. High rates of ventilation results in higher energy usage and energy costs for cold or hot climates while potentially increasing indoor air quality (IAQ) problems associated with high indoor humidity in warm-humid climates when the dehumidification capacity of the heating, ventilation, and air conditioning (HVAC) system is not designed for a high rate of entry of humid air. Low rates of ventilation, on the other hand, lead to higher indoor concentrations of a variety of indoorgenerated air pollutants. In office buildings with low ventilation rates, on average, occupants 
are less satisfied with indoor air quality and they experience more building-related adverse health symptoms (Seppanen and Fisk 2002).

Most building codes require that a minimum amount of outdoor air be provided to ensure adequate IAQ. To comply, ventilation systems typically are designed to operate with a fixed minimum outdoor air supply rate usually based on design occupancy that is much higher than occupancy levels during most of the time. While measured data on the minimum ventilation rates in existing offices are limited and subject to large measurement error, a survey of 100 U.S. office buildings supported by the U.S. Environmental Protection Agency provides the best available data (Persily and Gorfrain 2008). The measurements of ventilation rates in this survey collected when HVAC systems should be supplying minimum amounts of outdoor air were analyzed by the co-author of this report and indicate that, on average, minimum ventilation rates dramatically exceed code requirements that are typically 7.1 to $9.4 \mathrm{~L} / \mathrm{s}$ (15 to $20 \mathrm{cfm}$ ) per occupant depending on occupant density (CEC 2008; ASHRAE 2007). The high measured ventilation rates are partly a consequence of the low average occupant density in offices, relative to the design density, but may also be due to the absence, in most office buildings, of any real-time measurement and feed-back-control system for minimum ventilation rates.

To address the problems of too much or too little outdoor air, the HVAC system can use a DCV strategy to tailor the amount of outdoor air to the occupancy level. $\mathrm{CO}_{2}$ sensors have emerged as the primary technology for indirectly monitoring occupancy and implementing DCV: $\mathrm{CO}_{2}$ sensors monitor $\mathrm{CO}_{2}$ levels in the indoor air, and the HVAC system uses data from the sensors to adjust the amount of incoming outdoor air. If the HVAC system has an outdoor air economizer, the ventilation rate will be higher than indicated by the DCV controlled system when weather is mild.

Under the 2008 California Building Energy Efficiency Standards (Title 24) (CEC 2008), DCV is required for a space served by either a single zone system or a multi-zone system with DDC to the zone level that has an air-side economizer if the design occupant density is greater than or equal to 26.9 people per $100 \mathrm{~m}^{2}\left(40\right.$ people/1000 $\left.\mathrm{ft}^{2}\right)$, with some exceptions. General office spaces are not subject to the Title 24-2008 DCV requirement; however, given the evidence described above that minimum ventilation rates in offices without DCV are, on average, much higher than required in codes, a significant energy savings from DCV was hypothesized especially for the more severe California climates. The purpose of this assessment study was to estimate the energy savings potential and cost effectiveness of DCV for general office spaces through building performance simulation. The simulations assumed features of a typical medium size office buildings and were performed for typical climate zones of California.

Overviews of energy and environmental benefits of DCV systems, together with typical DCV design configurations and $\mathrm{CO}_{2}$ sensor technologies were well presented by IEA 1990, Fisk 1998, Carpenter 1996, Emmerich 2001, and Schell 1998. This assessment is different from other DCV energy savings analysis which used same design ventilation rates for the base cases as well as the DCV cases, while this assessment used the actual ventilation rates from two measurement approaches for the base cases, and used the code minimum ventilation rates for the DCV cases. This assessment serves to capture the boundaries of DCV life cycle cost savings for office 
buildings in California under various scenarios, which can be valuable reference to support the adoption of DCV for office spaces in future versions of Title 24.

\section{Methodology}

This assessment modeled the energy impact of DCV in terms of whole building energy performance which takes into account the integration and interaction of building components and systems. Instead of creating new building prototypes for this assessment, the DOE commercial building benchmark (Torcellini et al. 2008) for the medium-size office building was adopted. The medium-size office building was selected based on the US commercial building energy consumption survey (EIA 2003) indicating that office buildings were the most common building type, comprised the largest floor area, and consumed the most energy in the commercial building sector. The energy simulation model was modified to comply with the prescriptive requirements of Title 24-2008, including insulation level of building envelope, lighting power level, and HVAC equipment efficiencies. The Title 24 Standards occupancies were used, and DCV was added to the energy models. The energy usage difference between the base cases without DCV and the alternative cases with DCV are the HVAC energy savings due to the use of DCV, which include energy savings from cooling, heating, and supply fan.

The source energy use of the building was calculated, based on the electricity use and natural gas use, as follows for all five climate zones (Deru and Torcellini 2007):

Source Energy MJ = Electricity kWh * 3.6 * 3.095 + Natural Gas MJ * 1.092

Where 3.095 and 1.092 are the source factor of the electricity and natural gas respectively.

\subsection{The medium size office building}

The medium size office building has a rectangular shape about $50 \mathrm{~m} \times 33 \mathrm{~m}$ (Figure 1). It has three identical stories with a total floor area of $4982 \mathrm{~m}^{2}$. Each floor has five thermal zones: four perimeter ones and one core. All five zones are assumed to be general office occupancy. The window-wall-ratio is 33\%. The building does not have daylighting controls. The building is served by three packaged variable air volume (PVAV) systems with gas furnace for heating. One system serves one floor. Each of the three PVAV systems has an air side economizer which provides up to $100 \%$ of outdoor air for free cooling when indoor and outdoor conditions favor economizer operation. 

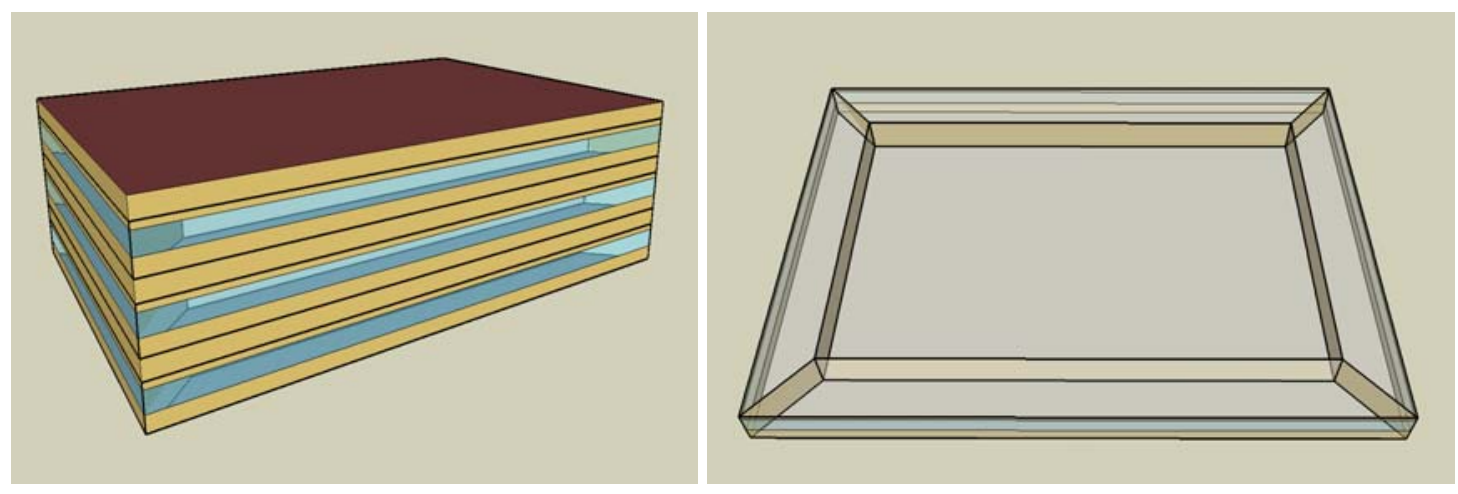

Figure 1 - Three Dimensional View the Office Building with Typical Floor Plan

The building size, shape, and operating schedules stay the same for all locations, but the building efficiency level varies with climate zone according to Title 24-2008 prescriptive requirements. Table 1 summarizes the internal loads and minimum ventilation rate for the office building based on the Title 24 Standards.

Table 1 - Internal Loads and Minimum Ventilation Rate of Office Buildings

\begin{tabular}{|l|l|l|l|l|l|l|l|}
\hline $\begin{array}{l}\text { Occupancy } \\
\text { Type }\end{array}$ & $\begin{array}{l}\text { Design } \\
\text { \#people } \\
\text { per } 100 \mathrm{~m}^{2}\end{array}$ & $\begin{array}{l}\text { Sensible } \\
\text { Heat } \\
\text { W/person }\end{array}$ & $\begin{array}{l}\text { Latent Heat } \\
\text { W/person }\end{array}$ & $\begin{array}{l}\text { Receptacle } \\
\text { Load W/m } / \mathrm{m}^{2}\end{array}$ & $\begin{array}{l}\text { Hot Water } \\
\text { Load } \\
\text { W/person }\end{array}$ & $\begin{array}{l}\text { Lighting } \\
\text { Power } \\
\mathrm{W} / \mathrm{m}^{2}\end{array}$ & $\begin{array}{l}\text { Ventilation } \\
\mathrm{L} / \mathrm{s} / \mathrm{m}^{2}\end{array}$ \\
\hline $\begin{array}{l}\text { Office } \\
\text { Buildings }\end{array}$ & 10.8 & 73 & 60 & 14.4 & 31 & 9.15 & 0.76 \\
\hline
\end{tabular}

Figure 2 shows the occupant schedules for weekdays and weekends with the percentage values representing the number of occupants in the building divided by the design number of occupants, converted to a percentage. These daily profiles are applicable year round, i.e., assuming no seasonal variations. 


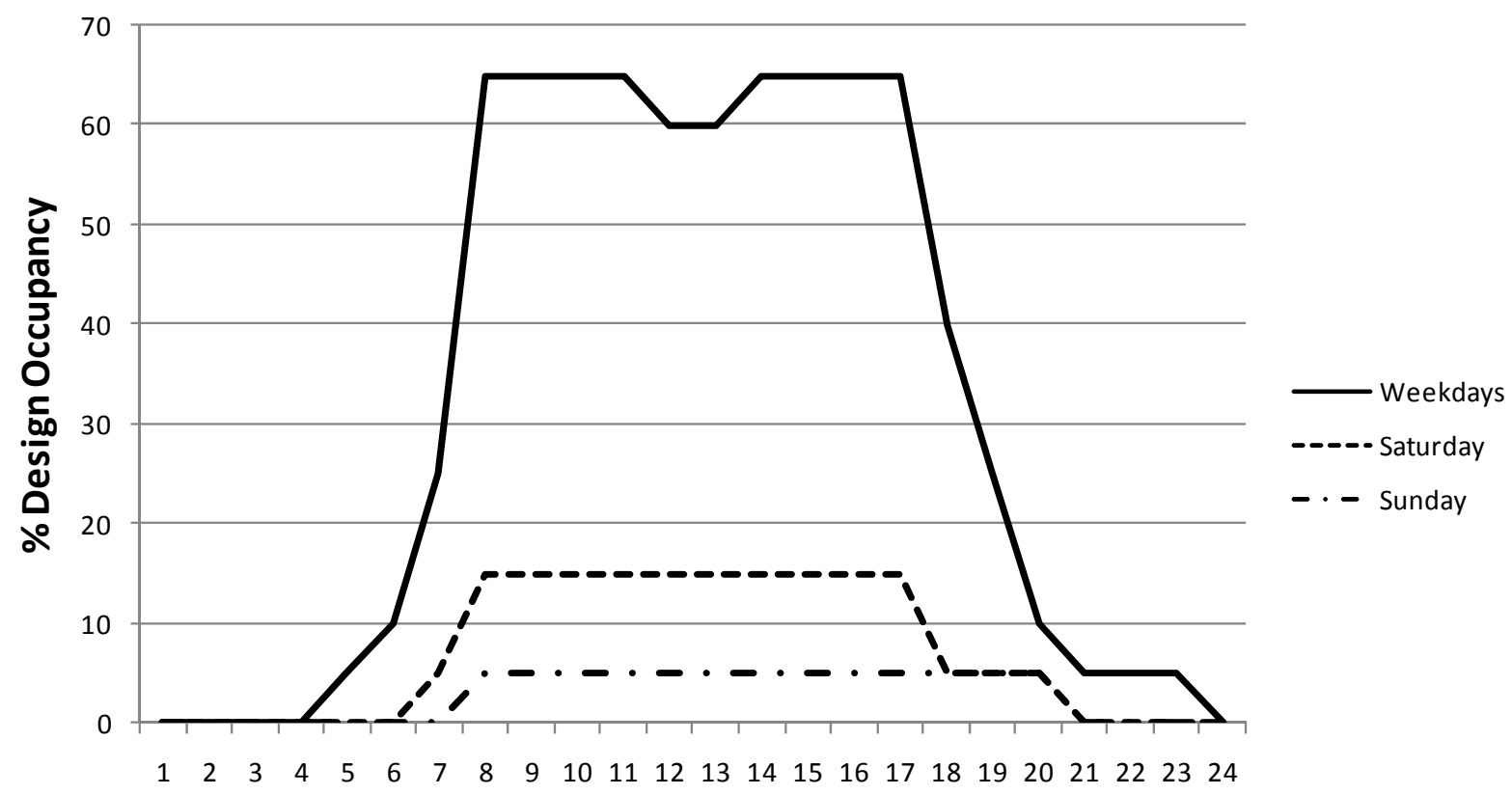

Hour

Figure 2 - Occupant Schedule of Office Building

Five cities representing typical climate regions of California were chosen and summarized in Table 2. The Title 24 Standards weather data for the chosen five climate zone was used in the simulations.

Table 2 - Five Typical California Climate Zones

\begin{tabular}{|l|c|l|}
\hline Description & California Climate Zone & Representative City \\
\hline North Coast & 3 & San Francisco \\
\hline South Coast & 6 & Los Angeles \\
\hline $\begin{array}{l}\text { Central } \\
\text { Valley }\end{array}$ & 12 & Sacramento \\
\hline Desert & 14 & China Lake \\
\hline Mountains & 16 & Mt. Shasta \\
\hline
\end{tabular}

\subsection{Outdoor air ventilation rates}

For the base cases without DCV, a constant outdoor air flow of either 13.2 or $38.2 \mathrm{~L} / \mathrm{s}$ (28 or 81 $\mathrm{cfm}$ ) per occupant was used based on average weekday occupancy when the building is occupied and ventilated. These two values of ventilation rates are based on the measured results from a survey of 100 representative U.S. office buildings and unpublished analyses by the coauthor of this report. The survey is the only known U.S. study of ventilation rates and other indoor air quality conditions in a large representative sample of office buildings. Ventilation and HVAC airflow data from this survey are described by Persily and Gorfain 
(2008). The survey took place for a broad range of weather conditions and the author analyzed data collected when the outdoor air temperature was above $22^{\circ} \mathrm{C}$ and, consequently, outdoor air supply rates should be at the minimum given the usual economizer control strategy. The resulting $13.2 \mathrm{~L} / \mathrm{s} /$ person average minimum ventilation rate is based on analyses of peak measured one-hour average carbon dioxide concentrations, assuming that occupants emit $0.0052 \mathrm{~L} / \mathrm{s}$ of $\mathrm{CO}_{2}$ and that the measured one-hour peak concentration is $80 \%$ of the true equilibrium $\mathrm{CO}_{2}$ concentration. The $38.2 \mathrm{~L} / \mathrm{s}$ per occupant average minimum ventilation rate is based on use of air velocity sensors to measure outdoor air flow rate, or from the difference between supply and recirculation air flow, both measured using velocity sensors. The two resulting average minimum ventilation rates are very different and, at present, it is not known which value is more accurate.

For the alternative cases with DCV, the space minimum outdoor air flow was calculated, consistent with the Title 24 Standards, as the larger of:

- $\quad 8.3 \mathrm{~L} / \mathrm{s} /$ person $(17.6 \mathrm{cfm} /$ person) times the current number of occupants present, where the current number of occupants equals the design occupancy multiplied by the occupant schedule percentage shown in Figure 2. The value of $8.3 \mathrm{~L} / \mathrm{s}$ per person corresponds to the ventilation rate necessary to maintain indoor carbon dioxide in an office building less than 600 ppm greater than the outdoor concentration assuming a carbon dioxide generation rate per occupant of $0.0052 \mathrm{~L} / \mathrm{s}$. This $600 \mathrm{ppm}$ maximum difference between indoor and outdoor concentration is specified for DCV in Title 24-2008.

and

- $\quad 0.76 \mathrm{~L} / \mathrm{s} / \mathrm{m}^{2}\left(0.15 \mathrm{cfm} / \mathrm{ft}^{2}\right)$ times the space floor area.

An average occupancy that is $50 \%$ of design occupancy was selected for the simulations to match typical practice in office buildings (Figure 2, Title 24 Standards). The $50 \%$ average weekday occupancy was used together with the two base case ventilation rates $(13.2$ or $38.2 \mathrm{~L} / \mathrm{s}$ per occupant) to set the constant minimum ventilation air flow for the base case simulations. For the DCV cases, the $\mathrm{CO}_{2}$ demand controlled ventilation system will, however, increase outdoor air ventilation rates when occupancy is at a higher level. The energy savings potential of demand controlled ventilation is a consequence of its ability to match the rate of outdoor air ventilation with actual occupancy, which is often less than peak design occupancy. With a design occupant density of 10.8 people $/ 100 \mathrm{~m}^{2}$ (10 people/1000 $\left.\mathrm{ft}^{2}\right)$ for office buildings, the design outdoor air flow based on the per person requirement is the larger of $0.76 \mathrm{~L} / \mathrm{s} / \mathrm{m}^{2}$ and a time varying rate that is always less than or equal to $0.89 \mathrm{~L} / \mathrm{s} / \mathrm{m}^{2}(8.3 \mathrm{~L} / \mathrm{s} /$ person X 10.8 people $/ 100 \mathrm{~m}^{2}$ ). Two alternate design occupancy levels representing a $50 \%$ and a $100 \%$ higher occupancy are included in the analysis. Table 3 summarizes the minimum outdoor air supply rates for all cases.

For both the base cases and the DCV cases, the PVAV systems have air side economizers as required by the Title 24 Standards. Therefore the actual outdoor air flow can exceed the minimum ventilation rate when economizers operate. 
Table 3 - Minimum Outdoor Air Requirement

\begin{tabular}{|c|c|c|c|c|c|c|}
\hline $\begin{array}{c}\text { Case } \\
\text { Description }\end{array}$ & $\begin{array}{c}\text { Design } \\
\text { Occupant } \\
\text { Density } \\
\text { \#people } \\
\text { per } 100 \\
\mathrm{~m}^{2}\end{array}$ & $\begin{array}{c}\text { Weekday } \\
\text { Average } \\
\text { Occupant } \\
\text { Density } \\
\text { \# people } \\
\text { per } 100 \\
\mathrm{~m}^{2}\end{array}$ & $\begin{array}{c}\text { Design OA } \\
\mathrm{L} / \mathrm{s} / \mathrm{m}^{2} \\
\text { based on } \\
13.2 \mathrm{~L} / \mathrm{s} / \mathrm{p} \\
\text { in base } \\
\text { cases or } 8.3 \\
\mathrm{~L} / \mathrm{s} / \mathrm{p} \text { in } \\
\text { DCV cases }\end{array}$ & $\begin{array}{c}\text { Design OA } \\
\mathrm{L} / \mathrm{s} / \mathrm{m}^{2} \\
\text { based on } \\
38.2 \mathrm{~L} / \mathrm{s} / \mathrm{p} \text { in } \\
\text { base cases } \\
\text { or } 8.3 \mathrm{~L} / \mathrm{s} / \mathrm{p} \\
\text { in } \mathrm{DCV} \\
\text { cases }\end{array}$ & $\begin{array}{c}\text { Title } 24 \\
\text { Required } \\
\text { Minimum } \\
\text { OA } \\
\mathrm{L} / \mathrm{s} / \mathrm{m}^{2}\end{array}$ & $\begin{array}{c}\text { Actual OA } \\
\text { Supply L/s/m² }\end{array}$ \\
\hline \multirow{3}{*}{ Base Cases } & 10.8 & 5.4 & 0.71 & 2.03 & NA & 0.71 or 2.03 \\
\hline & 16.1 & 8.0 & 1.07 & 3.10 & NA & 1.07 or 3.10 \\
\hline & 21.5 & 10.8 & 1.42 & 4.11 & NA & 1.42 or 4.11 \\
\hline \multirow{3}{*}{ DCV Cases } & 10.8 & 5.4 & $\begin{array}{c}0.89 \\
\text { (weekday } \\
\text { avg. }= \\
0.088 \text { ) }\end{array}$ & $\begin{array}{c}0.89 \\
\text { (weekday } \\
\text { avg. }= \\
0.088 \text { ) }\end{array}$ & 0.76 & $\begin{array}{c}\text { Varies with time } \\
(0.76 \text { to } 0.89)\end{array}$ \\
\hline & 16.1 & 8.0 & $\begin{array}{c}1.34 \\
\text { (weekday } \\
\text { avg. }= \\
0.132 \text { ) }\end{array}$ & $\begin{array}{c}1.34 \\
\text { (weekday } \\
\text { avg. = } \\
0.132 \text { ) }\end{array}$ & 0.76 & $\begin{array}{c}\text { varies with time } \\
(0.76 \text { to } 1.34)\end{array}$ \\
\hline & 21.5 & 10.8 & $\begin{array}{c}1.79 \\
\text { (weekday } \\
\text { avg. }= \\
0.176 \text { ) }\end{array}$ & $\begin{array}{c}1.79 \\
\text { (weekday } \\
\text { avg. }= \\
0.176 \text { ) }\end{array}$ & 0.76 & $\begin{array}{c}\text { varies with time } \\
(0.76 \text { to } 1.79)\end{array}$ \\
\hline
\end{tabular}

\subsection{Simulation tool}

EnergyPlus version 3.0, released in November 2008, was used to simulate the whole building energy performance of the selected medium size office building. The DCV algorithm implemented in EnergyPlus 3.0 is based on the calculation of space minimum outdoor air requirements for varying number of occupants and a constant component based on space floor area. EnergyPlus 3.0 calculates the system-level outdoor air requirement as the sum of space outdoor air flows, without considering zone air distribution effectiveness or system ventilation efficiency as required by ASHRAE standard 62.1-2007. This works fine for single zone systems or multi zone systems serving zones with same design occupancy and schedule. In this assessment, all spaces are assumed to be general offices with same design occupancy and schedule.

\subsection{Cost estimates}

In the DCV measure analysis (Taylor 2002) for the development of Title 24-2005, the DCV cost for a single zone system was estimated to be $\$ 575$ which included parts and labor. Adjusted for inflation and multiple zones served by a PVAV system, the DCV cost for each of the three 
PVAV systems were estimated to be $\$ 3085$ (average $\$ 617$ per zone $X 5$ zones). On the per building conditioned floor area basis, the DCV cost is $\$ 1.86 / \mathrm{m}^{2}$.

Based on a 15 year life cycle and 3\% discount rate for an installed DCV system, the present value (PV) of energy costs were estimated to be $\$ 1.37 / \mathrm{kWh}$ for electricity and $\$ 7.3 /$ Therm $(\$ 0.069 / \mathrm{MJ})$ for natural gas in California (Eley et al. 2002). These present values cost numbers were multiplied by the changes in annual energy consumption in the estimation of the present value of cost savings for the 15 year life cycle.

\section{Simulation Results}

Table 4 summarizes the simulation results and calculated energy usage and costs savings. The Design OA column lists the equivalent outdoor air rate per floor area converted from the outdoor air rate per occupant. The next three columns show the whole building annual energy use per conditioned floor area. The remaining columns indicate the energy and cost savings for $\mathrm{DCV}$ relative to the base cases. 
Table 4 - Simulation Results, Calculated Annual Energy Usage and Present Value of Costs Savings

\begin{tabular}{|c|c|c|c|c|c|c|c|c|c|c|c|}
\hline Location & $\begin{array}{l}\text { Design Occupant } \\
\text { Density } \\
\text { \#people/100 m² }\end{array}$ & Cases & $\begin{array}{r}\text { Design } \\
\mathrm{OA} \\
\mathrm{L} / \mathrm{s} / \mathrm{m}^{2}\end{array}$ & \begin{tabular}{|} 
Building \\
Electricity \\
Use \\
$\mathrm{kWh} / \mathrm{m}^{2}$
\end{tabular} & $\begin{array}{r}\text { Building } \\
\text { Gas Use } \\
\mathrm{MJ} / \mathrm{m}^{2}\end{array}$ & $\begin{array}{r}\text { Building } \\
\text { Source } \\
\text { Energy } \\
\mathrm{MJ} / \mathrm{m}^{2}\end{array}$ & $\begin{array}{r}\text { Building } \\
\text { Source } \\
\text { Energy } \\
\text { Savings \% }\end{array}$ & $\begin{array}{r}\text { HVAC } \\
\text { Energy } \\
\text { Cost PV } \\
\$ / \mathrm{m}^{2}\end{array}$ & $\begin{array}{r}\text { HVAC } \\
\text { Energy } \\
\text { Cost } \\
\text { Savings } \\
\mathrm{PV} \$ / \mathrm{m}^{2}\end{array}$ & $\begin{array}{l}\text { DCV } \\
\text { Cost } \\
\$ / m^{2}\end{array}$ & $\begin{array}{r}\text { DCV Life } \\
\text { Cycle } \\
\text { Cost } \\
\text { Savings } \\
\text { NPV } \$ / \mathrm{m}^{2}\end{array}$ \\
\hline \multirow{9}{*}{ CZ 3} & \multirow{3}{*}{10.8} & Base Case I (13.2 L/s/person) & 0.71 & 124.3 & 29.3 & 1448 & $-0.1 \%$ & 58.92 & -0.18 & 1.86 & $\begin{array}{l}-2.03 \\
\end{array}$ \\
\hline & & Base Case II (38.2 L/s/person) & 2.03 & 124.9 & 32.8 & 1459 & $0.7 \%$ & 60.08 & 0.98 & 1.86 & -0.88 \\
\hline & & DCV & 0.89 & 124.4 & 30.4 & 1450 & n.a. & 59.10 & n.a. & n.a. & n.a. \\
\hline & \multirow{3}{*}{16.1} & Base Case I (13.2 L/s/person) & 1.07 & 127.7 & 28.8 & 1487 & $0.1 \%$ & 63.64 & 0.17 & 1.86 & -1.68 \\
\hline & & Base Case II (38.2 L/s/person) & 3.10 & 131.1 & 32.4 & 1529 & $2.9 \%$ & 68.53 & 5.07 & 1.86 & 3.21 \\
\hline & & DCV & 1.34 & 127.7 & 27.7 & 1485 & n.a. & 63.46 & n.a. & n.a. & n.a. \\
\hline & \multirow{3}{*}{21.5} & Base Case I (13.2 L/s/person) & 1.42 & 131.3 & 28.1 & 1526 & $0.2 \%$ & 68.45 & 0.26 & 1.86 & -1.60 \\
\hline & & Base Case II (38.2 L/s/person) & 4.11 & 138.8 & 33.4 & 1617 & $5.8 \%$ & 79.09 & 10.90 & 1.86 & 9.04 \\
\hline & & DCV & 1.79 & 131.2 & 26.7 & 1523 & n.a. & 68.19 & n.a. & n.a. & n.a. \\
\hline \multirow{9}{*}{ CZ 6} & \multirow{3}{*}{10.8} & Base Case I (13.2 L/s/person) & 0.71 & 137.2 & 23.5 & 1589 & $-0.1 \%$ & 76.28 & -0.25 & 1.86 & -2.11 \\
\hline & & Base Case II (38.2 L/s/person) & 2.03 & 138.4 & 24.1 & 1603 & $0.7 \%$ & 77.91 & 1.38 & 1.86 & -0.48 \\
\hline & & DCV & 0.89 & 137.4 & 23.6 & 1591 & n.a. & 76.53 & n.a. & n.a. & n.a. \\
\hline & \multirow{3}{*}{16.1} & Base Case I (13.2 L/s/person) & 1.07 & 141.6 & 21.9 & 1637 & $0.0 \%$ & 82.10 & 0.07 & 1.86 & -1.79 \\
\hline & & Base Case II (38.2 L/s/person) & 3.10 & 144.1 & 22.7 & 1666 & $1.8 \%$ & 85.57 & 3.55 & 1.86 & 1.69 \\
\hline & & DCV & 1.34 & 141.5 & 21.8 & 1636 & n.a. & 82.03 & n.a. & n.a. & n.a. \\
\hline & \multirow{3}{*}{21.5} & Base Case I (13.2 L/s/person) & 1.42 & 145.9 & 20.9 & 1686 & $0.1 \%$ & 88.02 & 0.20 & 1.86 & -1.66 \\
\hline & & Base Case II (38.2 L/s/person) & 4.11 & 152.2 & 22.6 & 1758 & $4.2 \%$ & 96.68 & 8.85 & 1.86 & 6.99 \\
\hline & & DCV & 1.79 & 145.8 & 20.6 & 1684 & n.a. & 87.82 & n.a. & n.a. & n.a. \\
\hline \multirow{9}{*}{ CZ 12} & \multirow{3}{*}{10.8} & Base Case I (13.2 L/s/person) & 0.71 & 135.9 & 30.7 & 1582 & $-0.5 \%$ & 74.99 & -0.78 & 1.86 & -2.63 \\
\hline & & Base Case II $(38.2 \mathrm{~L} / \mathrm{s} /$ person) & 2.03 & 138.8 & 42.2 & 1627 & $2.3 \%$ & 79.65 & 3.89 & 1.86 & 2.03 \\
\hline & & DCV & 0.89 & 136.4 & 33.4 & 1590 & n.a. & 75.76 & n.a. & n.a. & n.a. \\
\hline & \multirow{3}{*}{16.1} & Base Case I (13.2 L/s/person) & 1.07 & 140.4 & 32.7 & 1635 & $0.3 \%$ & 81.30 & 0.55 & 1.86 & -1.31 \\
\hline & & Base Case II (38.2 L/s/person) & 3.10 & 144.5 & 41.9 & 1692 & $3.7 \%$ & 87.56 & 6.81 & 1.86 & 4.95 \\
\hline & & DCV & 1.34 & 140.1 & 30.6 & 1630 & n.a. & 80.75 & n.a. & n.a. & n.a. \\
\hline & \multirow{3}{*}{21.5} & Base Case I (13.2 L/s/person) & 1.42 & 144.8 & 35.3 & 1688 & $0.7 \%$ & 87.40 & 1.16 & 1.86 & -0.70 \\
\hline & & Base Case II $(38.2 \mathrm{~L} / \mathrm{s} /$ person) & 4.11 & 151.3 & 43.2 & 1771 & $5.4 \%$ & 96.95 & 10.71 & 1.86 & 8.85 \\
\hline & & DCV & 1.79 & 144.1 & 30.9 & 1676 & n.a. & 86.24 & n.a. & n.a. & n.a. \\
\hline \multirow{9}{*}{ CZ 14} & \multirow{3}{*}{10.8} & Base Case I (13.2 L/s/person) & 0.71 & 141.8 & 33.2 & 1652 & $-0.4 \%$ & 83.22 & -0.48 & 1.86 & -2.34 \\
\hline & & Base Case II (38.2 L/s/person) & 2.03 & 146.6 & 52.7 & 1728 & $4.0 \%$ & 91.17 & 7.47 & 1.86 & 5.61 \\
\hline & & DCV & 0.89 & 141.9 & 37.9 & 1658 & n.a. & 83.69 & n.a. & n.a. & n.a. \\
\hline & \multirow{3}{*}{16.1} & Base Case I (13.2 L/s/person) & 1.07 & 146.5 & 35.5 & 1707 & $0.6 \%$ & 89.78 & 1.31 & 1.86 & -0.55 \\
\hline & & Base Case II (38.2 L/s/person) & 3.10 & 153.3 & 52.7 & 1804 & $6.0 \%$ & 100.33 & 11.86 & 1.86 & 10.00 \\
\hline & & DCV & 1.34 & 145.5 & 35.2 & 1696 & n.a. & 88.47 & n.a. & n.a. & n.a. \\
\hline & \multirow{3}{*}{21.5} & Base Case I (13.2 L/s/person) & 1.42 & 151.4 & 42.0 & 1770 & $1.5 \%$ & 96.95 & 2.85 & 1.86 & 0.99 \\
\hline & & Base Case II (38.2 L/s/person) & 4.11 & 160.8 & 54.2 & 1891 & $7.8 \%$ & 110.66 & 16.56 & 1.86 & 14.70 \\
\hline & & DCV & 1.79 & 149.6 & 35.6 & 1743 & n.a. & 94.10 & n.a. & n.a. & n.a. \\
\hline \multirow{9}{*}{ CZ 16} & \multirow{3}{*}{10.8} & Base Case I (13.2 L/s/person) & 0.71 & 127.9 & 59.4 & 1522 & $-0.3 \%$ & 65.98 & 0.21 & 1.86 & -1.64 \\
\hline & & Base Case II $(38.2 \mathrm{~L} / \mathrm{s} /$ person & 2.03 & 128.9 & 113.0 & 1592 & $4.1 \%$ & 71.11 & 5.34 & 1.86 & 3.48 \\
\hline & & DCV & 0.89 & 127.2 & 70.9 & 1526 & n.a. & 65.76 & n.a. & n.a. & n.a. \\
\hline & \multirow{3}{*}{16.1} & Base Case I (13.2 L/s/person) & 1.07 & 131.1 & 69.7 & 1569 & $1.0 \%$ & 71.06 & 1.60 & 1.86 & -0.25 \\
\hline & & Base Case II $(38.2 \mathrm{~L} / \mathrm{s} /$ person) & 3.10 & 133.2 & 118.0 & 1645 & $5.6 \%$ & 77.26 & 7.80 & 1.86 & 5.94 \\
\hline & & DCV & 1.34 & 130.1 & 66.0 & 1554 & n.a. & 69.46 & n.a. & n.a. & n.a. \\
\hline & \multirow{3}{*}{21.5} & Base Case I (13.2 L/s/person) & 1.42 & 134.5 & 87.7 & 1627 & $2.1 \%$ & 76.90 & 2.96 & 1.86 & 1.11 \\
\hline & & Base Case II $(38.2 \mathrm{~L} / \mathrm{s} /$ person) & 4.11 & 138.5 & 124.1 & 1713 & $7.0 \%$ & 85.03 & 11.10 & 1.86 & 9.24 \\
\hline & & DCV & 1.79 & 133.3 & 68.6 & 1592 & n.a. & 73.94 & n.a. & n.a. & n.a. \\
\hline
\end{tabular}

Figures 3 to 5 show DCV life cycle cost savings in net present value NPV $\$ / \mathrm{m}^{2}$ for the three design occupancy levels. 


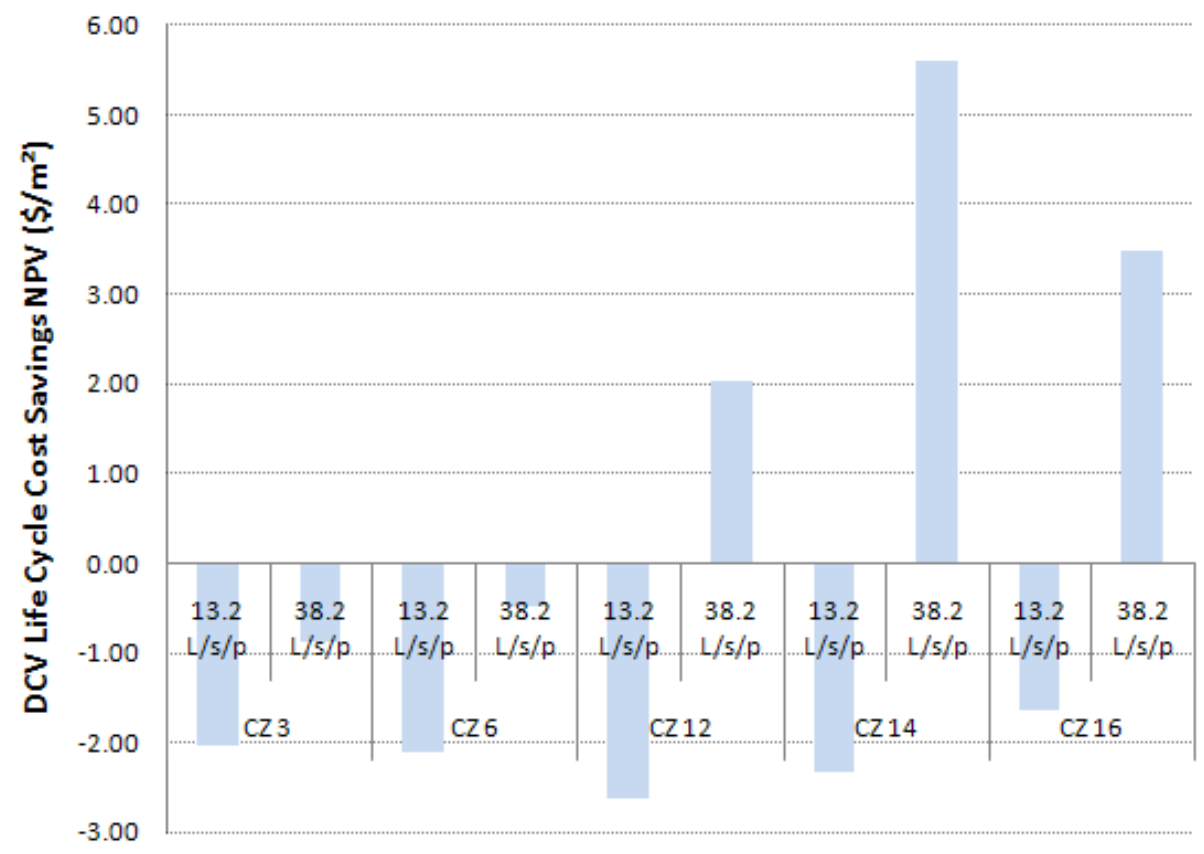

Figure 3 - DCV life cycle cost savings with design occupancy of 10.8 people / $100 \mathrm{~m}^{2}$ and base case minimum ventilation rates of 13.2 or $38.2 \mathrm{~L} / \mathrm{s}$ per person.

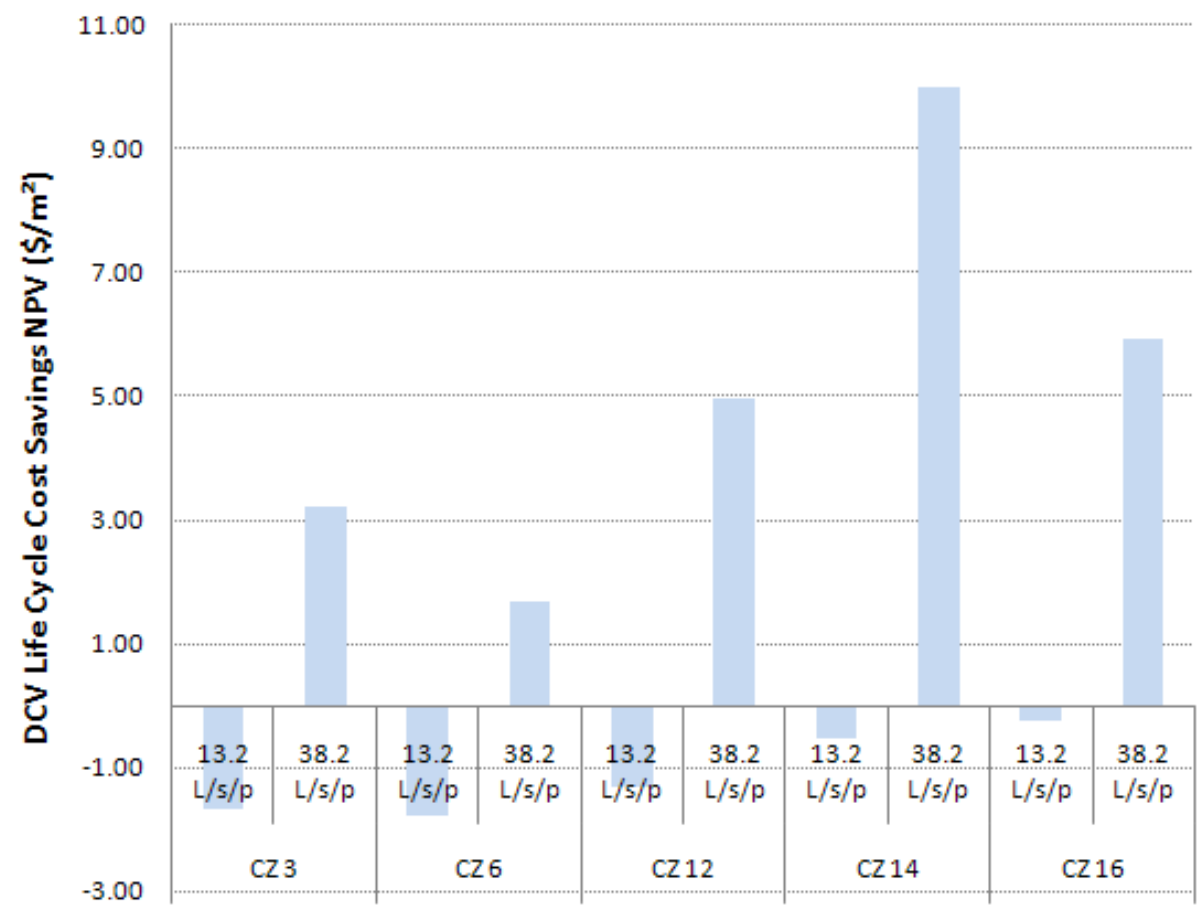

Figure 4-DCV life cycle cost savings with a design occupancy of 16.1 people / $100 \mathrm{~m}^{2}$ and base case minimum ventilation rates of 13.2 or $38.2 \mathrm{~L} / \mathrm{s}$ per person. 


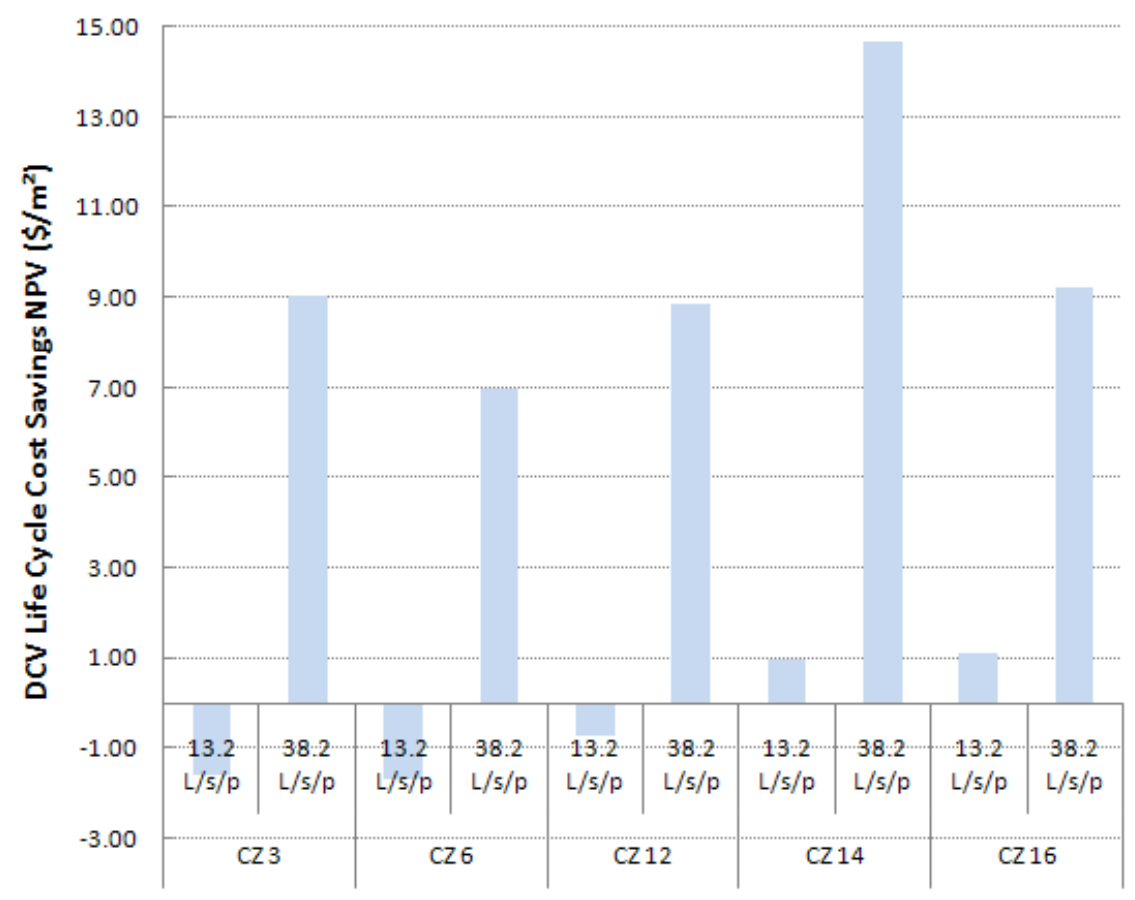

Figure 5 - DCV life cycle cost savings with a design occupancy of 21.5 people / $100 \mathrm{~m}^{2}$ and base case minimum ventilation rates of 13.2 or $38.2 \mathrm{~L} / \mathrm{s}$ per person.

From Figures 3 to 5, it can be seen that with the reference outdoor ventilation rate of 13.2 $\mathrm{L} / \mathrm{s} /$ person, only for climate zones 14 and 16 do the calculations indicate a marginal life cycle cost savings for DCV when the design occupancy is at 21.5 people / $100 \mathrm{~m}^{2}$. This is probably due to the fact that the DCV cases have higher design ventilation rates than the cases without DCV at a fixed ventilation rate of $13.2 \mathrm{~L} / \mathrm{s} /$ person for all three occupant density levels. For the base case with a reference ventilation rate of $38.2 \mathrm{~L} / \mathrm{s} /$ person, the without-DCV cases always have higher ventilation rates than the DCV cases for all three occupant density levels.

From Figure 3 at design occupancy of 10.8 people per $100 \mathrm{~m}^{2}$, DCV is cost effective (positive NPV savings) with the reference outdoor ventilation rate of $38.2 \mathrm{~L} / \mathrm{s} /$ person for climate zones 12 , 14 , and 16. The largest estimated savings is $\$ 5.62 / \mathrm{m}^{2}$ in climate zone 14 , followed by $\$ 3.49 / \mathrm{m}^{2}$ in climate zone 16 , and $\$ 2.03 / \mathrm{m}^{2}$ in climate zone 12 .

From Figure 4 at design occupancy of 16.1 people per $100 \mathrm{~m}^{2}$, DCV is cost effective with the reference outdoor ventilation rate of $38.2 \mathrm{~L} / \mathrm{s} /$ person in all five climate zones, with the largest savings of NPV $\$ 10.0 / \mathrm{m}^{2}$ in climate zone 14 , followed by $\$ 5.94 / \mathrm{m}^{2}$ in climate zone $16, \$ 4.95 / \mathrm{m}^{2}$ in climate zone $12, \$ 3.22 / \mathrm{m}^{2}$ in climate zone 3 , and $\$ 1.69 / \mathrm{m}^{2}$ in climate zone 6 . The savings are much higher than those at design occupancy of 10.8 people per $100 \mathrm{~m}^{2}$.

From Figure 5 at design occupancy of 21.5 people per $100 \mathrm{~m}^{2}$, DCV is cost effective with the reference outdoor ventilation rate of $13.2 \mathrm{~L} / \mathrm{s} /$ person in climate zones 3,6 , and 12 . The largest savings with the reference outdoor ventilation rate of $38.2 \mathrm{~L} / \mathrm{s} /$ person is NPV $\$ 14.7 / \mathrm{m}^{2}$ in climate zone 14 , followed by $\$ 9.24 / \mathrm{m}^{2}$ in climate zone $16, \$ 9.04 / \mathrm{m}^{2}$ in climate zone $3, \$ 8.85 / \mathrm{m}^{2}$ in climate zone $12, \$ 7.00 / \mathrm{m}^{2}$ in climate zone 6 . The savings are much higher than those at design occupancy of 16.1 people per $100 \mathrm{~m}^{2}$. 
The largest estimated DCV life cycle cost savings and energy savings occur for climate zone 14 (desert) --this is due to the significant heating demand in winter and cooling in summer. For cooling dominant climates like climate zone 6 (south coast), the DCV savings mostly come from the reduction of outdoor air cooling during summer, while for heating dominant climates like climate zone 16 (mountains), the DCV savings mostly come from the reduction of outdoor air heating during winter

Figures 2 to 4 do not show the base case minimum ventilation rates above which DCV become cost effective. To determine these pivot minimum ventilation rates under the Title 24 occupant density of 10.8 people per $100 \mathrm{~m}^{2}$, two more base case ventilation rates were studied for each of the five climate zones. Error! Reference source not found. summarizes the simulation results and the calculated pivot minimum ventilation rates using quadratic curve fit for the data points. It can be seen that under the Title 24 Standards office occupancy, the DCV becomes cost effective when the base case minimum ventilation rate is greater than 42.5, 43.0, 24.0, 19.0, and $18.0 \mathrm{~L} / \mathrm{s}$ per person for climate zone $3,6,12,14$, and 16 respectively.

Table 5 - Determination of Base Case Minimum Ventilation Rates Above Which DCV Become Cost Effective with Title 24 Occupant Density of 10.8 people per $100 \mathrm{~m}^{2}$

\begin{tabular}{|c|c|c|c|}
\hline Climate Zone & $\begin{array}{r}\text { Base Case } \\
\text { Minimum OA } \\
\text { (L/s/person) } \\
\end{array}$ & $\begin{array}{r}\text { DCV Life } \\
\text { Cycle Cost } \\
\text { Savings NPV } \\
\$ / \mathrm{m}^{2} \\
\end{array}$ & $\begin{array}{r}\text { Base Case Minimum } \\
\text { Ventilation Rates } \\
\text { (L/s/person) Above } \\
\text { Which DCV Become } \\
\text { Cost Effective }\end{array}$ \\
\hline \multirow{4}{*}{ CZ 3} & 13.2 & -2.03 & \multirow{4}{*}{42.5} \\
\hline & 25.5 & -1.50 & \\
\hline & 38.2 & -0.88 & \\
\hline & 47.1 & 0.84 & \\
\hline \multirow{4}{*}{ CZ 6} & 13.2 & -2.11 & \multirow{4}{*}{43.0} \\
\hline & 25.5 & -1.19 & \\
\hline & 38.2 & -0.48 & \\
\hline & 47.1 & 0.36 & \\
\hline \multirow{4}{*}{ CZ 12} & 13.2 & -2.63 & \multirow{4}{*}{24.0} \\
\hline & 20.7 & -0.69 & \\
\hline & 30.2 & 1.01 & \\
\hline & 38.2 & 2.03 & \\
\hline \multirow{4}{*}{ CZ 14} & 13.2 & -2.34 & \multirow{4}{*}{19.0} \\
\hline & 20.7 & 0.47 & \\
\hline & 30.2 & 3.87 & \\
\hline & 38.2 & 5.61 & \\
\hline \multirow{4}{*}{ CZ 16} & 13.2 & -1.64 & \multirow{4}{*}{18.0} \\
\hline & 20.7 & 0.60 & \\
\hline & 30.2 & 2.84 & \\
\hline & 38.2 & 3.48 & \\
\hline
\end{tabular}




\section{Discussion}

This analysis has estimated the energy and life cycle cost impacts of using DCV in general office spaces in various California climate zones. For reference, when DCV was not employed the fixed minimum outdoor air ventilation rate was assumed to equal either 13.2 or $38.2 \mathrm{~L} / \mathrm{s}$ per occupant. Three design occupant densities were employed; however, per the occupancy schedule in Table 3, the actual peak occupant density was only $65 \%$ of the design occupant density. The analyses indicate the potential for significant energy and life-cycle cost savings from DCV in general office spaces if the base case fixed ventilation rate without DCV is $38.2 \mathrm{~L} / \mathrm{s}$ per occupant. While this ventilation rate comes from measured survey data, a much lower rate of $13.2 \mathrm{~L} / \mathrm{s}$ per occupant is derived from the same survey based on application of a different measurement method. With this lower reference ventilation rate, the modeling indicates that DCV is not cost effective except in the most severe California climates and in buildings with a high design occupant density of 21.5 persons per $100 \mathrm{~m}^{2}$. Unfortunately, it is not known which of these estimates of base case ventilation rates without DCV is more accurate. Also, the survey that yielded the ventilation rate data is from buildings throughout the U.S., while data from a representative survey of California office buildings would serve as a better reference. An accurate measurement of minimum ventilation rates in typical existing California office buildings is a multi-year project, and is a good candidate for future research.

While the main source of uncertainty is the uncertain base case ventilation rate as described above, other sources of uncertainty should be mentioned. The analysis was performed for the prototypical office building and results would vary somewhat to a small extent with building size and features. DCV capital costs and future energy costs are uncertain. If current inflation trends continue, the cost effectiveness of demand controlled ventilation may improve over time. Energy prices have been increasing faster than the general inflation rate (U.S. Census Bureau 2009). While we have not identified cost trends for the $\mathrm{CO}_{2}$ sensors used in demand controlled ventilation, we suspect that the cost increase of mass produced electronic equipment is less than the general inflation rate. The EnergyPlus program used for the modeling computes the ventilation rates in buildings with DCV based on the number of occupants present in the building while actual DCV systems respond to the indoor concentration of occupant-generated $\mathrm{CO}_{2}$ which lags in time behind occupancy. The projected energy savings would be larger, but probably only modestly larger, if EnergyPlus modeled DCV based on occupant-generated $\mathrm{CO}_{2}$.

\section{Conclusion}

In California climates, DCV in general office spaces is expected to save significant energy and be cost effective only if typical ventilation rates without DCV are very high relative to the minimum rate required in codes. Under the Title 24 Standards office occupancy, DCV becomes cost effective when the base case minimum ventilation rate is greater than 42.5, 43.0, 24.0, 19.0, and $18.0 \mathrm{~L} / \mathrm{s}$ per person for climate zone $3,6,12,14$, and 16 respectively. Until the large uncertainties about ventilation rates without DCV are reduced, the case for requiring DCV in general office spaces will be a weak case. 


\section{References}

[1] ASHRAE (2007). ASHRAE Standard 62.1-2007: Ventilation for acceptable indoor air quality, American Society of Heating, Refrigerating, and Air Conditioning Engineers, Atlanta.

[2] California Energy Commission (CEC 2008). California building energy efficiency standards for residential and nonresidential buildings, CEC-400-2008-01-CMF.

[3] Carpenter SE (1996). Energy and IAQ impacts of $\mathrm{CO}_{2}$-based demand-controlled ventilation, ASHRAE Transactions 102(2): 80-88.

[4] Deru M, Torcellini P (2007). Source energy and emission factors for energy use in buildings, Technical report NREL/TP-550-38617.

[5] Eley Associates and New Building Institute (2002). Utility cost forecasts: years 2005 through 2035.

[6] Emmerich SJ, Persily AK (2001). State-of-the-Art Review of $\mathrm{CO}_{2}$ Demand Controlled Ventilation Technology and Application, NISTIR 6729, US National Institute of Standards and Technology.

[7] Energy Information Administration (EIA 2003). Commercial Building Energy Consumption Survey.

[8] Fisk WJ, Almeida AT (1998). Sensor-based demand-controlled ventilation: a review, Energy and Buildings, 29(1): 35-45.

[9] International Energy Agency (IEA 1990), Demand-controlled ventilating systems: state of the art review.

[10] Persily AK, Gorfain J (2008). Analysis of ventilation data from the U.S. Environmental Protection Agency Building Assessment Survey and Evaluation (BASE) Study, NISTIR7145-Revised, National Institute for Standards and Technology: Bethesda. MD.

[11] Schell MB, Turner SC, Shim RO (1998). Application of $\mathrm{CO}_{2}$-based demand-controlled ventilation using ASHRAE Standard 62: optimizing energy use and ventilation, ASHRAE Transactions, 104(2): 1213-1225.

[12] Seppanen O, Fisk WJ (2002). Association of ventilation system type with SBS symptoms in office workers, Indoor Air, 12(2): 98-112.

[13] Taylor Engineering (2002). Demand controlled ventilation - measure analysis for Title 24-2005.

[14] Torcellini P, Deru M, Griffith B, Benne K, Halverson M, Winiarski D, Crawley D (2008). DOE commercial building benchmark models, In: Proceedings of the 2008 ACEEE Summer Study on Energy Efficiency in Buildings, Conference paper NREL/CP-55043291. 
[15] U.S. Census Bureau, Statistical abstract of the United States - 2009. 2009, U.S. Census Bureau: Washington, D.C. 